\title{
Extraction of Ni (II) by Modified Magnetite Nanocomposite Adsorbent
}

\author{
Nikhat Neyaz ${ }^{1}$, Weqar. A. Siddiqui ${ }^{2}$ \\ Department of applied sciences and humanities, Faculty of Engineering and Technology,Jamia Millia Islamia- New Delhi-25
}

\begin{abstract}
The present study investigates the extraction of $\mathrm{Ni}$ (II) from water by applying surface modified silica-coated magnetite nanocomposite as an adsorbent. Magnetite nanoparticles are synthesized by co precipitation method, using ferric and ferrous salts in basic medium. Silica coating is done by Stober method of sol-gel hydrolysis, using precursor TEOS. Surface of silica-coated magnetite nanoparticles are modified with hexa-dentate ligand (EDTA) via acid catalyzed sol-gel hydrolysis. Size of the magnetite nanocomposite is determined by XRD and SEM and is found to be 15-18 $\mathrm{nm}$ in range. Silica coating and functionalisation with EDTA are confirmed by EDX and FT-IR characterization. Magnetic property is studied by VSM and the nanocomposites are found to be super paramagnetic at room temperature. Batch experiment is carried out to study the adsorption kinetics and mechanism of nickel adsorption by magnetite nanocomposite. The adsorption process is found to be $\mathrm{pH}$ dependent and equilibrium is attained within 15 minutes. Adsorption data is well fitted with Langmuir adsorption model. Reaction parameters such as $\mathrm{pH}$, amount of adsorbent, time taken to complete adsorption are studied and optimized. Regeneration study indicates that magnetite nano composite follows successive adsorption and desorption cycle and retain original metal removal capacity till five cycles are completed.
\end{abstract}

Keywords: Magnetite nanocomposites, Superparamagnetism, Adsorption kinetics, Optimized reaction parameters, Adsorption-desorption cycle.

\section{Introduction}

$\mathrm{m}$ hydroxide, Tetra ethoxy silane, glacial acetic acid, ethylene-di-ammine tetra acetic acid, Clean and safe water for all is the major concern for any country. Industrialization and westernization contribute to pollution of surface and ground water [1]. Major pollutants are toxic heavy metals, inorganic and organic compounds. For toxic heavy metals industries such as electroplating, metal processing, mining, tanneries, pharmaceuticals, pesticides, organic chemicals, rubber and plastic lumber and wood products [2] are responsible. Heavy metals which are generally released by industries are $\mathrm{Cu}, \mathrm{Ni}, \mathrm{Cr}, \mathrm{Cd}, \mathrm{As}, \mathrm{Hg}, \mathrm{Pb}, \mathrm{As}, \mathrm{Ag}, \mathrm{Au}$, U et.c Most of the heavy metals discharge into the water are found to be toxic, carcinogenic and cause a serious threat to the human health. Many kinds of adsorbent has been commercialized since a long time for the removal of toxic metals from waste water Generally these adsorbents are made from highly porous materials and thus providing a high surface area for better adsorption. But intra particle diffusion causes low adsorption rate and capacity especially for macromolecules. Thus developing an adsorbent with large surface area and small diffusion resistance is of great importance in environmental remediation. Advent of nanotechnology has solved this problem to a large extent by synthesizing various kinds of nanomaterials for the treatment of waste water. So far magnetic nanomaterials have been explored extensively in water remediation fields. Various researches [3-4] have proved that magnetic nanomaterials especially magnetite and maghemite are widely used in removal of organic, inorganic and heavy metal impurities from water. Magnetic nanomaterials apart from having high surface area to volume ratio, having so many unique properties which make remediation process economical, efficient and environmentally friendly, such as least toxic, biodegradable, and magnetically removal of pollutants[5-6].
Present study also investigated the application of modified magnetite for the removal of $\mathrm{Ni}$ (II) from water. It was found that bare magnetite nanoparticles adsorb negligible amount of metal compared to modified magnetite. Modification of the surface dramatically enhanced the adsorption capacity due to the presence of multifunctional groups which are helpful in making chelates or complexes with metal ions [7$10]$.

\section{Materials and Methods}

\subsection{Materials}

For synthesis purpose all reagents such as ferrous chloride and ferric chloride, sodium, glycerol were of analytical grade reagents.

\subsection{Methods}

\subsubsection{Preparation method of EDTA-functionalized silica-} coated magnetite nanocomposites

Aqueous solution of ferrous and ferric salts were taken in 1: 2 molar ratio and co precipitated in the presence of base $(\mathrm{NaOH}, 1 \mathrm{M})$ on ultra sonic stirrer at fixed temperature $\left(90^{\circ}\right)$ and stirring rate. Stirring was continued till complete precipitation occurs. Reaction was completed for two hours and further aging was done for half an hour. In this synthesis process the striking point was to synthesize magnetite in the absence of inert atmosphere by maintaining high temperature of reaction medium. Silica coating was done by using precursor TEOS by sol-gel hydrolysis [11]. Further functionalisation with EDTA was done in acidic medium via sol-gel hydrolysis also.

\subsubsection{Sample analysis method}

Surface morphology and size of the synthesized nanocomposites was determined by SEM. FT-IR spectral analysis showed the confirmation of functionalisation of 


\section{International Journal of Science and Research (IJSR) \\ ISSN (Online): 2319-7064 \\ Index Copernicus Value (2013): 6.14 | Impact Factor (2014): 5.611}

EDTA on the surface of silica-coated magnetite nanocomposite and also confirmed the adsorption of copper on the surface. Sample composition and elemental analysis was done by EDX spectral analysis .Super paramagnetic property [12] was determined by using VSM.

\section{Adsorption Experiment}

Adsorption experiment was carried by stirring fixed amount of a nanocomposite as a nanosorbent (.1 gram) with $10 \mathrm{ml}$ of $.1 \mathrm{M}$ solution of nickel salts for 15 minutes at room temperature to attain equilibrium. Metal loaded adsorbent was separated magnetically. The concentration of un adsorbed metal ions was found out with the help of calibration graph of nickel salt solution at a fixed wavelength with varying initial metal concentration. After the equilibration the $\mathrm{pH}$ of the reaction medium was changed hence prior to find out the metal concentration of filtrate, $\mathrm{pH}$ should be stabilized. The amount of adsorbed metal concentration can be found out by applying formula$\mathrm{C}_{\mathrm{a}}=\mathrm{C}_{\mathrm{i}}-\mathrm{C}_{\mathrm{f}}$ where $\mathrm{C}_{\mathrm{i}}=$ initial concentration, $\mathrm{C}_{\mathrm{f}}=$ final concentration. The amount of metal ions $\left(\mathrm{q}_{t}\right)$ adsorbed in a given time $(\mathrm{t})$ can be calculated as $\mathrm{q}_{\mathrm{t}}=\left\{\mathrm{C}_{\mathrm{o}}-\mathrm{C}_{\mathrm{t}}\right\} \mathrm{V} / \mathrm{m}$. Where $\mathrm{C}_{\mathrm{O}}, \mathrm{C}_{\mathrm{t}}, \mathrm{V}, \mathrm{m}$ are initial concentration of metal ions, concentration of metal ions after time $t$, volume of the solution, mass of the adsorbent. Percentage recovery factor $(\% \mathrm{R})$ was calculated by the following equation- $\% \mathrm{R}=$ $\mathrm{C}_{\mathrm{a}} / \mathrm{C}_{\mathrm{O}} \times 100$ where $\mathrm{C}_{\mathrm{a}}, \mathrm{C}_{\mathrm{o}}$ are adsorbed concentration and initial concentration of metal ions.

\subsection{Adsorption isotherm}

Sorption isotherm [13] was determined by mixing .1 gram adsorbent with $10 \mathrm{ml}$ of metal solutions with varying initial metal concentration ions ranging from $.01 \mathrm{M}-.1 \mathrm{M}$, followed by stirring for 15 minutes at room temperature to attain equilibrium. The $\mathrm{pH}$ of the reaction medium was set at 7.5 as an optimized value. After adsorption, the metal loaded sorbent was magnetically separated and final metal concentration in supernatant was determined by the calibration graph as shown in Figure 6.4, plotted by diluting concentration of standard solution in a fixed ratio and corresponding absorption is measured with the help of UVVis spectrophotometer at a fixed wavelength $\left(\lambda_{\max }\right)$. The concentration of adsorbed metal ions was calculated as a difference between the initial concentration in the solution and the final concentration after the equilibration. The amount of metal ions adsorbed at time $\mathrm{t}$, qt in $\mathrm{mg} / \mathrm{gm}$ is calculated as a mass balance equation- $\mathrm{q}_{\mathrm{t}}=\left\{\mathrm{C}_{\mathrm{o}}-\mathrm{C}_{\mathrm{t}}\right\} \mathrm{V} / \mathrm{m}$. Where $\mathrm{C}_{\mathrm{O}}, \mathrm{C}_{\mathrm{t}}, \mathrm{V}, \mathrm{m}$ are initial concentration of metal ions, concentration of metal ions after time $t$, volume of the solution, mass of the adsorbent.

\subsection{Effect of Adsorbent Dose}

To investigate the effect of amount adsorbent on the adsorption capacity, $10 \mathrm{ml}$ of, $1 \mathrm{M}$ metal solutions were mixed with varying quantity of adsorbents followed by stirring for 15 minutes at room temperature and at fixed $\mathrm{pH}$ (7.5). After the reaction and separation, the residual metal ion concentration was determined.

\subsection{Effect of $\mathrm{pH}$}

The effect of $\mathrm{pH}$ on adsorption capacity was tested by taking. 1 gram of adsorbent with $10 \mathrm{ml}$ of $.1 \mathrm{M}$ metal solutions with varying $\mathrm{pH}$ values ranging from $2-7.5$, at room temperature, followed by stirring for 15 minutes. After adsorption and separation residual metal concentrations were determined.

\subsection{Effect of Time}

To study the effect of time on adsorption capacity, .1 gram of adsorbent was mixed with $10 \mathrm{ml}$ of .1M metal solutions, followed by stirring at room temperature for various time intervals ranging from 5-18 minutes.

\subsection{Desorption and Reusability}

Desorption study was carried out by using .1 $\mathrm{M} \mathrm{HCl}$ solution as an eluant for eluting the adsorbed metal ions from the adsorbent. For this fixed amount of metal loaded adsorbent was mixed with $10 \mathrm{ml}$ of $\mathrm{HCl}$, followed by ultrasonic stirring at room temperature for 15 minutes for desorption of metal ions. After complete elution the unloaded adsorbent was separated magnetically and metal concentration in supernatant was determined. Recovered adsorbent reused till five recycling process successfully

\section{Result and Discussions}

\subsection{Characterization of EDTA-functionalized silica - coated magnetite nanocomposites}

Surface morphology and average size were determined by SEM image as shown in Figure 6.1(a). It was found that it is spherical in shape; average size of the nanocomposite was found to be $18 \mathrm{~nm}$. While the nickel adsorbed on the surface of magnetite nanocomposites is shown in Figure 6.1(b).

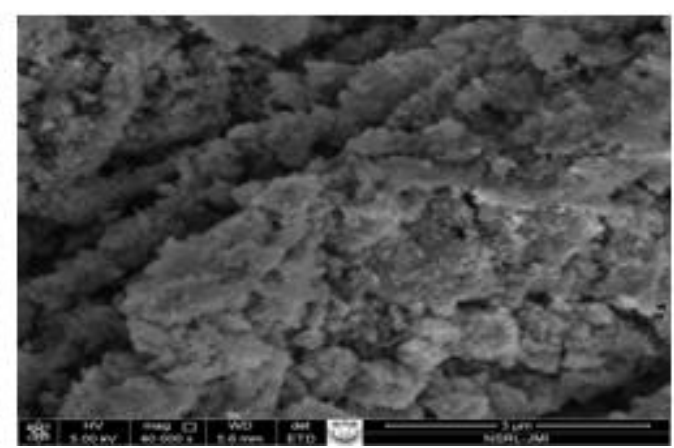

Figure 1: (a) SEM image of EDTA-Si-Coated magnetite nanocomposites, (b) Nickel metal adsorbed on the surface of magnetite nano composites 


\section{International Journal of Science and Research (IJSR) \\ ISSN (Online): 2319-7064 \\ Index Copernicus Value (2013): 6.14 | Impact Factor (2014): 5.611}

FT-IR spectra are shown in Figure 6.2. The characteristic frequencies of $-\mathrm{COOH}$, and $-\mathrm{NH}_{2}$ functional groups at 1595 $\mathrm{cm}^{-1}$. and $3365 \mathrm{~cm}^{-1}$ are clearly shown in Figure 6.2 (a). The red shift of peak of $-\mathrm{COOH}$ functional group from $1595 \mathrm{~cm}^{-1}$ to $1402 \mathrm{~cm}^{-1}$ clearly suggests the complexation or chelation of nickel metal ions with carboxyl functional groups.

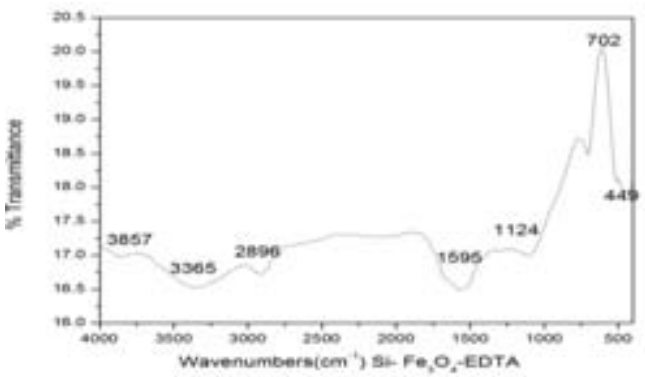

Figure 2: (a) FT-IR spectra of magnetite nanosorbent (b)

Chemical composition analysis is done by EDX, as shown in Figure 6.3. The functionalisation of EDTA is also confirmed by EDX analysis as intensity of the peaks of oxygen was increased dramatically as shown in Figure.6.3 (a). Adsorption of $\mathrm{Ni}$ (II) on the surface of magnetite is also confirmed by EDX as adsorption peak of nickel is clearly

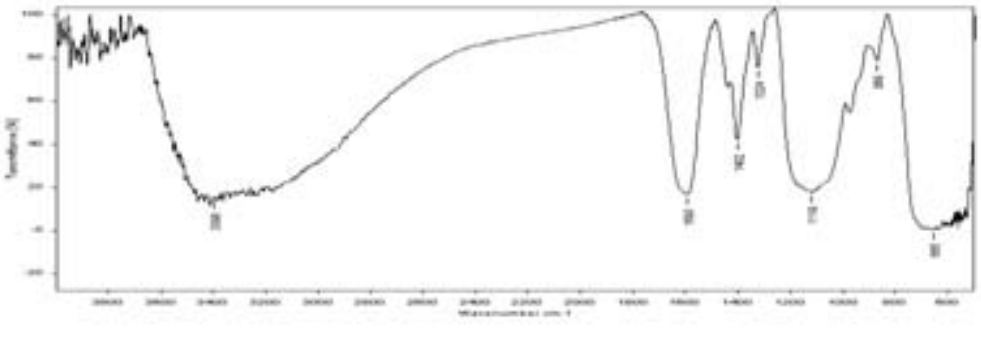

(b) FT-IR spectra of nickel adsorbed magnetite nanosorbent. found in EDX spectra as shown in Figure 6.3 (b). VSM study as shown in Figure 6.4 reveals the super paramagnetic property of magnetite nanocomposite. Although modification of magnetite nanocomposites decreases the magnetic property but enough to separate metal loaded adsorbent magnetically by applying external magnetic field.
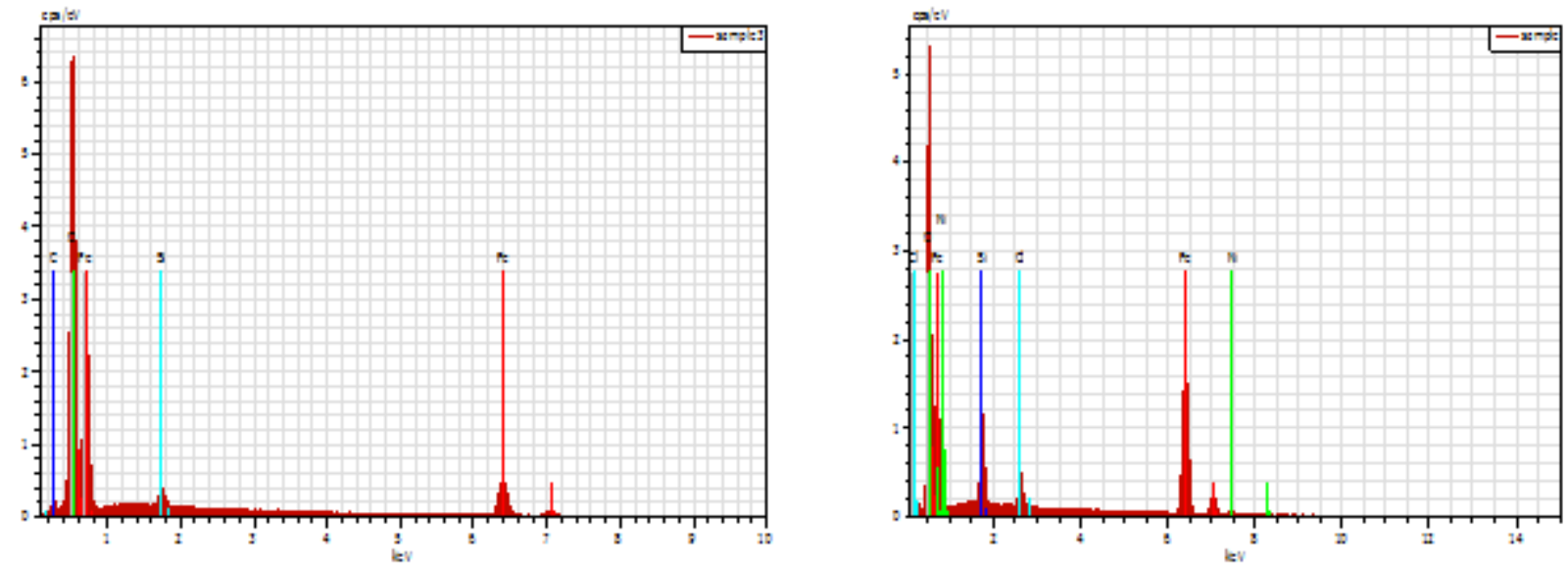

Figure 3: (a) EDX spectra of magnetite nanocoposites (b) Ni-adsorbed magnetite nanocomposites

\subsection{Adsorption Isotherm}

Langmuir adsorption isotherm as shown in Figure 6.5, assumes that the monolayer adsorption occurs on a homogenous surface of the adsorbent with no lateral interaction between adsorbate molecules. Langmuir adsorption equation is described as below

$$
1 / q_{e}=1 / q_{m} b C_{e}+1 / q
$$

where qe is the equilibrium adsorption capacity of adsorbent toward $\mathrm{Cu}(\mathrm{II})(\mathrm{mg} / \mathrm{g}), \quad \mathrm{Ce}$ is the equilibrium $\mathrm{Cu}(\mathrm{II})$ concentration in solution $(\mathrm{mg} / \mathrm{L}), \mathrm{qm}$ is the maximum capacity of adsorbent $(\mathrm{mg} / \mathrm{g})$, and $\mathrm{b}$ is the the Langmuir adsorption constant pertaining to the energy of adsorption $(\mathrm{L} / \mathrm{mg})$. The value of $\mathrm{q}_{\mathrm{e}}$ is calculated as $2.64 \mathrm{~mol} / \mathrm{gram}$ for .19 gram adsorbent. The $\% \mathrm{R}$ value is calculated as $91 \%$ for .19 gram adsorbent.

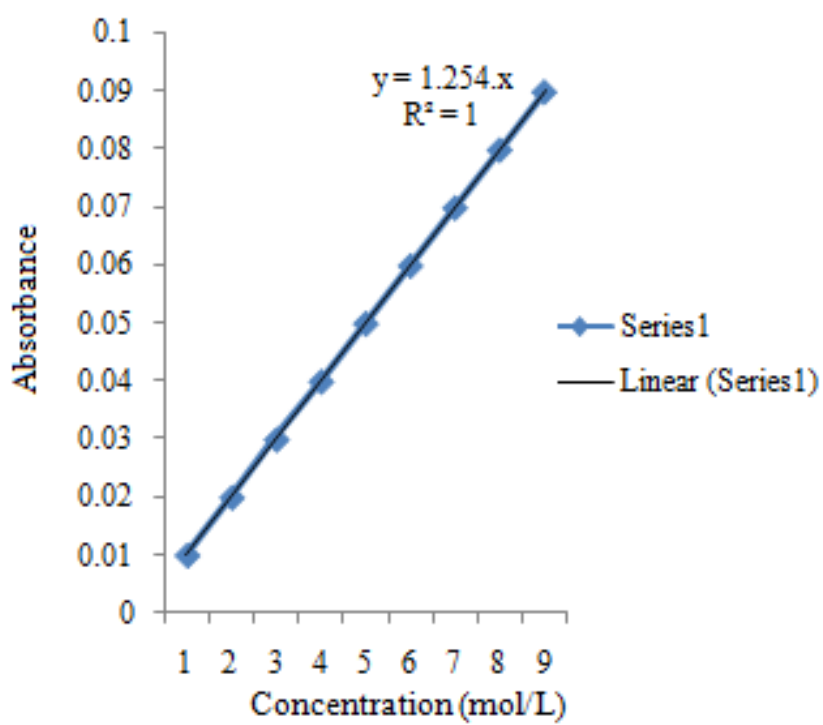

Figure 4: Calibartion graph for Ni(II) at $615 \mathrm{~nm}$ wavelength. 


\section{International Journal of Science and Research (IJSR) \\ ISSN (Online): 2319-7064}

Index Copernicus Value (2013): 6.14 | Impact Factor (2014): 5.611

\subsection{Effect of pH and its optimization in adsorption of $\mathrm{Ni}$} (II) ions

The reaction parameter $\mathrm{pH}$ was an important factor to reach the equilibration of the reaction or completion of the reaction [14]. It was observed that adsorption was highly $\mathrm{pH}$ dependent as in the beginning when $\mathrm{pH}$ was 2-4 in range; adsorption was found to be negligible. As soon as $\mathrm{pH}$ was increased from 4-5, adsorption was also increased, it continued to increase till $\mathrm{pH}$ was reached at 7.5 as shown in Figure 6.6. Adsorption was maximum at $\mathrm{pH} 7.5$ and started decreasing beyond this value. This suggests that at lower $\mathrm{pH}$, concentration of $\mathrm{H}^{+}$ions is higher and it competes for chelation or complexation with metal ions on the reaction sites. At higher $\mathrm{pH}, \mathrm{OH}^{-}$would dominate in reaction medium and metal ions would have a tendency to get precipitated in the form of metal hydroxides. Hence a fewer metal ions would escape to bind with reaction sites. For this reason $\mathrm{pH}$, 7.5 had been taken as an optimized value for further adsorption process. Adsorption mechanism was found to be ion exchange and electrostatic attraction during the process of adsorption.

\section{pH Vs \% R}

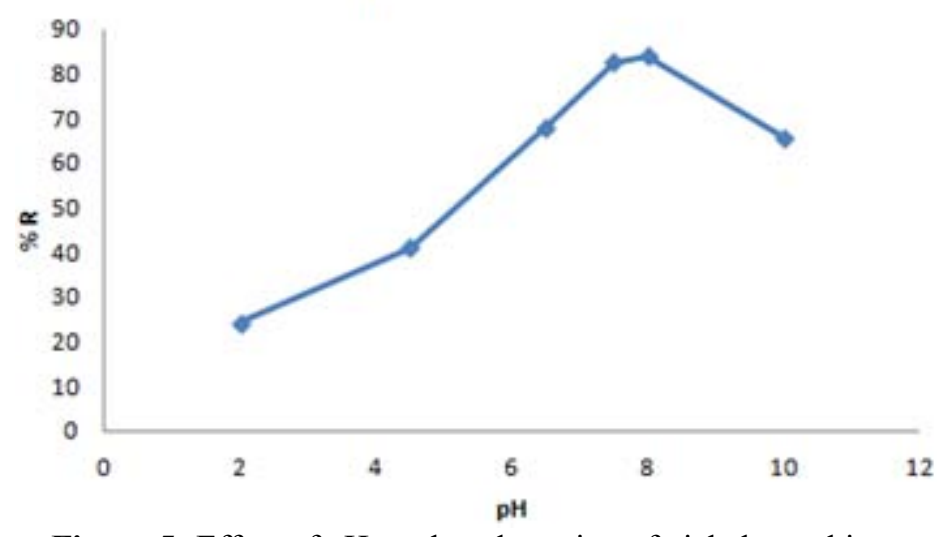

Figure 5: Effect of $\mathrm{pH}$ on the adsorption of nickel metal ions

\subsection{Effect of adsorbent and its optimized condition}

The adsorption process is dependent upon the amount of adsorbent.as shown in Figure 6.7. The adsorption is negligible in the beginning as the adsorbent is very low (.03gram to .05gram) in quantity. As soon as amount of adsorbent is increased (.06gram to .19gram) the more metals are happened to be adsorbed hence adsorption capacity is increased very fast. After a certain point (.19 gram) where the maximum adsorption is reported, it starts decreasing. Hence .19 grams are taken as an optimized amount for the maximum adsorption. The reason for the decrease in adsorption capacity beyond the optimize quantity is the fully occupied reaction sites and no more sites are available for further chelation or complexation.

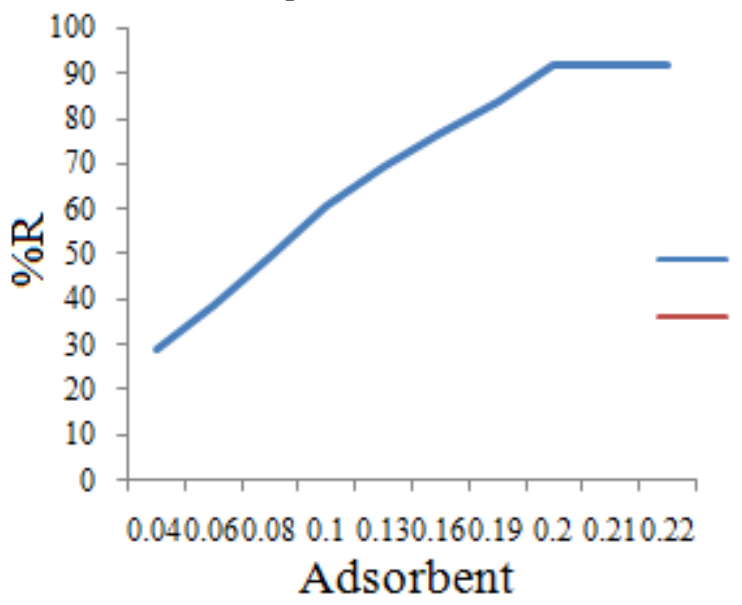

Figure 6: Effect of adsorbent on the adsorption of nickel metal ions
4.5 Effect of time on the adsorption capacity and its optimized condition

The adsorption process is time dependent as shown in Figure 6.8. In the beginning adsorption of metal ions is almost negligible between time intervals 2-6 minutes. After that when time is increased for 8-15 minutes adsorption process increases and at 15 minutes maximum adsorption is reported. After 15 minutes further increased in time for a fixed amount of adsorbent (.19 gram), adsorption starts decreasing. The reason behind this is no available reaction sites for further complexation with metal ions. Hence 15 minutes have to be considered as an optimized time for the adsorption.

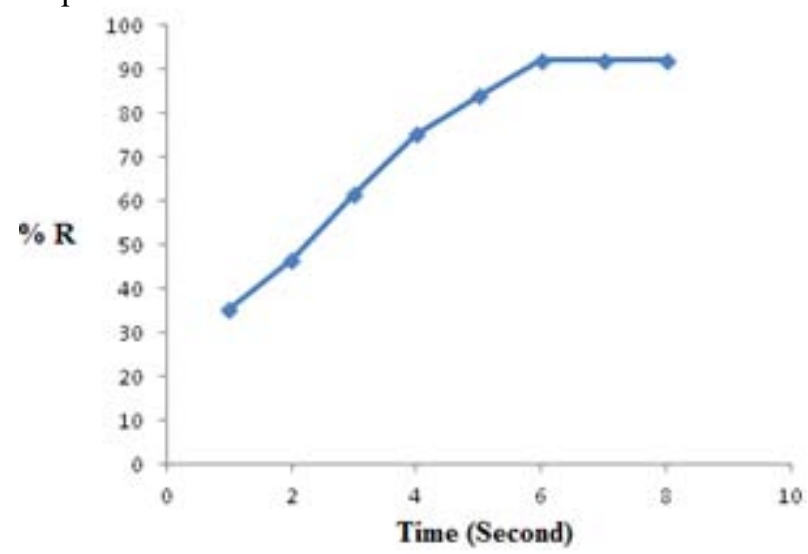

Figure 7: Effect of time on the adsorption of nickel metal ions 


\section{International Journal of Science and Research (IJSR) \\ ISSN (Online): 2319-7064}

Index Copernicus Value (2013): 6.14 | Impact Factor (2014): 5.611

\section{Desorption and Regeneration Study}

Desorption study is carried out by mixing $10 \mathrm{ml}$ of $.1 \mathrm{M} \mathrm{HCl}$ with .19 gram adsorbent in a beaker and followed by stirring on ultrasonic stirrer for 15 minutes at room temperature. After that magnetic nanosorbent is separated by applying external magnetic field and the concentration of the eluted metal ions in the filtrate are measured with the help of calibration graph of nickel metal ions by measuring the absorbance using UV-Visible Spectrophotometer. It is observed that the desorption of nickel metal ions in the beginning are $90-95 \%$. Elution of metal ions is quite satisfactory till fifth cycles.

\section{Conclusion}

Present research work concludes that the EDTAfunctionalized-Silica-coated magnetite nanocomposite was synthesized by co-precipitation method followed by sol-gel hydrolysis. SEM and EDX study provided the conclusive evidence of their successful synthesis. VSM study had proved that the synthesized nanocomposite is super paramagnetic in nature at room temperature; hence it was separated easily by applying external magnetic field. Adsorption study was carried out successfully and it was observed that adsorption was $\mathrm{pH}$ dependent and adsorption mechanism was noted as ion exchange as well as electrostatic binding. Reaction parameters were optimized for the maximum adsorption and it was found that 19 gram adsorbent was enough to extract $90 \% \mathrm{Ni}$ (II) at $\mathrm{pH} 7.5$ within 15 minutes. Hence modified magnetite nano composite as an adsorbent would be better option in remediation technology of waste water especially polluted with toxic heavy metals.

\section{References}

[1] Keshav K. Deshmukh ,Sangamner Nagarpalika Arts, D.J. Malpani Commerce and B.N. Sarda Science College, Sangamner, Dist. Ahmednagar, Ms, India, (2013), Impact of Human Activities on the Quality of Groundwater from Sangamner Area, Ahmednagar District, Maharashtra, India, International Research Journal of Environment Sciences, 2(8), 66-74,

[2] Schwarzenbach R P, Egli T, Hofstetter T B, Von Gunten U, and Wehrli B, (2010), Global water pollution and human health, Annual Review of Environment and Resources, 35, 109-136,

[3] Rizwan Ullah, Riffat Naseem Malik and Abdul Qadir, (2009), Assessment of groundwater contamination in an industrial city, Sialkot, Pakistan African Journal of Environmental Science and Technology. 3 (12),. 429446 ,

[4] Masciangioli T, and Zhang, W X, (2003), Environmental technologies at the nanoscale, Environ. Sci. Technol., 102A, 102-108.

[5] Oliveira L C A, et al. (2003), Clay-iron oxide magnetic composites for the adsorption of contaminant in water, Appl. Clay Sci., 22, 169-177

[6] $\mathrm{Hu} \mathrm{J}$, Chen G H, and M C Lo, (2005), Selective removal and recovery of various heavy metals by maghemite nanoparticles, Proc, Int Symp on
Nanotechnology in Environmental Protection and Pollution, Asia Pacific Nanotechnology Forum APNF, Bangkok, Thailand.

[7] Hu J, M C Lo, and Chen G H, 2004, Removal of Cr(VI ),by magnetite nanoparticle,Water Sci. Technol., $50,12,139-146$.

[8] Yunfeng Xu, Chengcai Li, Xia Zhu, Wei E. Huang, Dayi Zhang, (2014),Application of magnetic nanoparticles in drinking water purification, $13,(8)$, 2023-2029

[9] Yuan Liu, Tao Chen, Cuichen Wu, Liping Qiu , Rong $\mathrm{Hu}$, Juan Li, Sena Cansiz, Liqin Zhang, Cheng Cui , Guizhi Zhu, Mingxu You, Tao Zhang, and Weihong Tan , (2014), Facile Surface Functionalization of Hydrophobic Magnetic Nanoparticles, J. Am. Chem. Soc, 136 (36), 12552 12555

[10] White BR, Stackhouse BT, Holcombe JA, (2009), Magnetic $\gamma$-Fe2O3 nanoparticles coated with poly-1cysteine for chelation of $\mathrm{As}(\mathrm{III}), \mathrm{Cu}(\mathrm{II}), \mathrm{Cd}(\mathrm{II}), \mathrm{Ni}(\mathrm{II})$, $\mathrm{Pb}(\mathrm{II})$ and $\mathrm{Zn}(\mathrm{II}), \mathrm{J}$ Hazard Mater), 161,848-853.

[11] Huang CZ, Hu B, (2008), Silica-coated magnetic nanoparticles modified with $\gamma$ mercaptopropyltrimethoxysilane for fast and selective solid phase extraction of trace amounts of $\mathrm{Cd}, \mathrm{Cu}, \mathrm{Hg}$, and $\mathrm{Pb}$ in environmental and biological samples prior to their determination by inductively coupled plasma mass spectrometry, Spectrochim Acta B, 63,437-444

[12] Suleiman JS, Hu B, Peng HY, Huang CZ, (2009), Separation/preconcentration of trace amounts of $\mathrm{Cr}, \mathrm{Cu}$ and $\mathrm{Pb}$ in environmental samples by magnetic solidphase extraction with Bismuthiol-II-immobilized magnetic nanoparticles and their determination by ICP-OES,Talanta, 7, 1579-1583

[13] Kadirvelu K., Tharmaraiselvi K, and Namasivayam C, (2001), Adsorption of nickel_II_ from aqueous solution onto activated carbon prepared from coirpith, Sep Purif Technol, 24,3, 497-505.

[14] Kannan N, and Sundaram M M,( 2001), Kinetics and mechanism of removal of methylene blue by adsorption on various carbons, A comparative study,Dyes Pigm., 51,1, 25-40. 